\title{
Dental caries experience, care index and restorative index in children with learning disabilities and children without learning disabilities; a systematic review and meta- analysis
}

Mark D. Robertson ${ }^{1 *}$ (D) Falk Schwendicke ${ }^{2}$, Mariana Pinheiro de Araujo ${ }^{3}$, John R. Radford ${ }^{1}$, Jenny C. Harris ${ }^{4}$, Scott McGregor ${ }^{5}$ and Nicola P. T. Innes ${ }^{1}$

\begin{abstract}
Background: Children with learning disabilities (CLD) have worse health outcomes than children with no learning disabilities (CNLD). This systematic review compared caries experience and met dental care need for CLD to CNLD using Decayed, Missing, Filled Permanent Teeth (DMFT) and decayed, missing/extracted, filled primary teeth (dmft/ deft), care index $(\mathrm{Cl})$, and restorative index (RI) values.

Methods: Without date or language restrictions four databases were searched for; cross-sectional studies comparing caries experience and Cl/ RI in CLD matched to groups of CNLD. Screening and data extraction were carried out independently and in duplicate. Risk of bias was assessed using the Newcastle-Ottawa Scale. Metaanalyses were carried out (random effects model).
\end{abstract}

Results: There were 25 articles with 3976 children (1 to 18 years old), from 18 countries, fitting the inclusion criteria. Children with; Down syndrome were investigated in 11 studies, autism in 8 and mixed learning disabilities in 6 . The overall mean DMFT for CLD was 2.31 (standard deviation \pm 1.97 ; range 0.22 to 7.2$)$ and for CNLD was $2.51( \pm 2.14 ; 0.37$ to 4.76). Using standardised mean difference (SMD), meta-analysis showed no evidence of a difference between CLD and CNLD ( $n=16$ studies) for caries experience (SMD $=-0.43 ; 95 \% \mathrm{Cl}=-0.91$ to 0.05$)$. This was similar for sub-groups of children with autism (SMD $=-0.28 ; 95 \% \mathrm{Cl}=1.31$ to 0.75$)$ and mixed disabilities $(\mathrm{SMD}=0.26 ; 95 \% \mathrm{Cl}=-0.94$ to 1.47$)$. However, for children with Down syndrome, caries experience was lower for CLD than CNLD (SMD $=-0.73 ; 95 \% \mathrm{Cl}=-1.28$ to -0.18$)$. For primary teeth, mean $\mathrm{dmft} / \mathrm{deft}$ was 2.24 for CLD and 2.48 for CNLD ( $n=8$ studies). Meta-analyses showed no evidence of a difference between CLD and CNLD for caries experience across all disability groups (SMD $=0.41 ; 95 \% \mathrm{Cl}=-0.14$ to 0.96 ), or in sub-groups: Down syndrome $(S M D=0.55 ; 95 \% \mathrm{Cl}-=-0.40$ to 1.52$)$, autism $(S M D=0.43 ; 95 \% \mathrm{Cl}=-0.53$ to 2.39$)$ and mixed disabilities ( $\mathrm{SMD}=-0.10 ; 95 \% \mathrm{Cl}=-0.34$ to 0.14 ). The studies' risk of bias were medium to high.

Conclusion: There was no evidence of a difference in caries levels in primary or permanent dentitions for CLD and CNLD. This was similar for learning disability sub-groups, except for Down syndrome where dental caries levels in permanent teeth was lower. Data on met need for dental caries was inconclusive.

Trial registration: The protocol was published in PROSPERO: CRD42017068964 (June 8th, 2017).

Keywords: Children, Dental caries, Learning disability, Care index, Restorative index, Systematic review

\footnotetext{
* Correspondence: m.r.robertson@dundee.ac.uk

'School of Dentistry, University of Dundee, Park Place, Dundee DD1 4HR, UK

Full list of author information is available at the end of the article
}

(c) The Author(s). 2019 Open Access This article is distributed under the terms of the Creative Commons Attribution 4.0 International License (http://creativecommons.org/licenses/by/4.0/), which permits unrestricted use, distribution, and reproduction in any medium, provided you give appropriate credit to the original author(s) and the source, provide a link to the Creative Commons license, and indicate if changes were made. The Creative Commons Public Domain Dedication waiver (http://creativecommons.org/publicdomain/zero/1.0/) applies to the data made available in this article, unless otherwise stated. 


\section{Background}

Disability affects approximately 1 million children in the UK, with around " $8 \%$ of children aged 7-15 having specific educational needs associated with intellectual, developmental, communication, sensory or physical impairments in England alone" [1]. A learning disability can be defined as a reduced intellectual ability leading to challenges with everyday tasks and situations [2, 3]. It affects people for the duration of their lives and often requires significant support from carers to interact with others [4]. The disability's impact on different aspects of life varies from person to person, depending on factors such as support from family, friends and carers but can significantly impact their healthcare access, ability to understand information, comply with instructions and cope with treatment. Not only do people with learning disabilities suffer from co-morbidities but they have worse health outcomes than their non-learning disabled counterparts in areas of health not related to their disability [5]. This is in part because they are more likely to have additional health problems [6] but can also be associated with suboptimal care from health care professionals and social services [5]. Differences in health status between people with learning disabilities and people without learning disabilities represents a genuine health inequality that is largely avoidable and entirely unjust [7].

Recent systematic reviews of those with intellectual disabilities have found conflicting evidence regarding their oral hygiene status. Oral hygiene was found to be poorer than in adults without learning disabilities [8]. In children with autism, oral hygiene has been found to be poorer and caries prevalence higher compared to the general population [9] and there is a question over whether children with Down syndrome have lower levels of caries as has been previously accepted [10]. Overall, caries experience of children with learning disabilities (CLD) compared to children without learning disabilities (CNLD) has not been clearly established, and the most recent review [11] did not limit the inclusion criteria to only children with learning disabilities. No previous reviews have attempted to look at the levels and type of dental care provided for managing carious teeth in CLD compared to CNLD. The care index and restorative index are measures of previous management of dental caries and build on the data from decayed, missing and filled teeth. As such, they give information on the delivery of dental services, inequalities in access, amount, and type of care that has been received (extraction or restorative). The well-established relationship between socio-economic status and dental caries [12], in addition to links between social deprivation and children with learning disabilities [13], suggests that they could suffer a greater burden of dental caries and unmet need where the disease exists.
The objective of this systematic review was to assess dental caries experience; and type and extent of dental care in children with learning disabilities in comparison to children without learning disabilities using DMFT/ $\mathrm{dmft}$, care index $(\mathrm{CI})$, and restorative index $(\mathrm{RI})$ values.

\section{Methods}

The review was developed in accordance with Preferred Reporting Items for Systematic Review and MetaAnalysis Protocols (PRISMA-P) [14].

The review protocol was published in PROSPERO (June 8th, 2017; http://www.crd.york.ac.uk/PROSPERO/ display_record.php?ID=CRD42017068964).

\section{Searches}

There were no language or date restrictions imposed on the search. We recognised that terminology used to describe and group people with learning disabilities depends on cultural and historic contexts and evolves over time. Therefore we were inclusive of politically contested language while building search strategies.

The literature search strategies were developed using medical subject headings $(\mathrm{MeSH})$ and text words related to dental caries in children and to disabilities. We searched four databases: MEDLINE (OVID interface, 1949 to June 2017); PubMed (1946 to June 2017); Scopus (Elsevier interface, 1996 to June 2017, 1823 to June 2017 without references); and Web of Science (1900 to June 2017) to find relevant literature using the following search strategy, which was designed for MEDLINE (Ovid) and afterwards revised for each database. The search was updated in December 2018:

(Child [MeSH] OR child* OR pediatric OR paediatric) AND ("pediatric dentistry" $[\mathrm{MeSH}]$ OR dentistry OR dental OR teeth OR tooth OR oral OR "oral health"[$\mathrm{MeSH}$ ) AND ("special needs" OR "special care" OR learning disabilities OR learning difficulties OR "learning disorders"[MeSH] OR "intellectual disability"[MeSH] OR mental retardation OR mentally retarded OR mongol* $^{*}$ OR disab* OR autism OR autistic OR autistic spectrum OR "autistic spectrum disorder" [MeSH] OR Asperger syndrome OR "down syndrome"[MeSH] OR down* syndrome OR trisomy 21 OR dental care for disabled $[\mathrm{MeSH}]$ ) AND (caries OR carious OR tooth decay OR lesions OR saliva* OR "salivation" $[\mathrm{MeSH}]$ OR "dental caries"[MeSH]) AND (DMF OR DMFS OR DMFT) AND (restorative index OR RI OR care index OR CI).

\section{Inclusion criteria}

Study design Observational studies with data on caries experience collected through clinical examination of participants. Studies where CLD were compared to general population values were excluded. 
Participants/ population CLD (with or without physical disabilities) and a similar group of CNLD.

\section{Study selection}

Two reviewers screened titles and abstracts, independently and in duplicate, against the inclusion and exclusion criteria, and, where there was disagreement, consensus was achieved through discussion with a third reviewer. Full texts were obtained for all titles which were thought to meet the inclusion criteria. Reviewers were not blinded to journal titles, study authors or institutions.

\section{Data extraction}

Data extraction forms were piloted and feedback resulted in them being revised. The revised forms were used to collect data independently and in duplicate by two trained and calibrated reviewers.

\section{Data extracted}

- Study characteristics (title, reference, author(s) and year of publication);

- Methodology (Characteristics of data collection (e.g. data collectors, part of a regular epidemiological programme etc.); caries data collection system, and threshold for caries diagnosis (e.g. D2, D3 etc.);

- Year of data collection;

- Participant inclusion and exclusion criteria;

- Participant demographic information:

- Age groups were recorded. As the upper age limit for childhood varies geographically and between cultures, all groups were included up to the age of 19. Note was taken of the age group and range included in each study; and

- The type of disability was recorded as reported and decisions made around the appropriateness of grouping different disabilities together.

- Number of participants and whether or not a sample size was calculated.

o Study setting (country, region, national/ local/ international, and clinical setting).

- Outcome data for caries levels; and CI and RI.

The reviewers reached consensus through discussion where there was any discrepancy in data extraction.

\section{Data synthesis and meta-analysis}

The mean DMFT/dmft for each study and the CI and RI were extracted or calculated from the data. The CI is a measure of the proportion of carious teeth that have been managed with restorations or by extraction and is defined as the number of restored teeth as a proportion of the total number of decayed (D), missing (M) and filled $(\mathrm{F})$ teeth $(\mathrm{CI}=\mathrm{F} / \mathrm{D}+\mathrm{M}+\mathrm{F})$. It provides an epidemiological measure of how much treatment has been provided to manage the disease. The RI is the proportion of carious teeth that have been filled as a proportion of the decayed and filled teeth $(F / D+F)$. We planned to carry out subgroup analyses for primary/ permanent dentition, age and type of disability (after subgrouping depending on the data).

Included studies that reported DMFT and dmft values with variance estimates $(n=16)$ were included in the meta-analyses [15-30]. Generic-inverse variance method of meta-analysis was performed using Comprehensive Meta-Analysis 2.2.064 (Biostat, NJ, USA). Our outcome measure was the standardised mean difference (SMD), accounting for: (1) the difference in magnitude in caries experience across included age groups; and (2) the fact that some studies included deft, not dmft.

Two analyses on caries experience were performed, one for permanent teeth and one for primary teeth. Meta-analyses on RI/CI were not feasible given any kind of variance estimates were missing from all included studies.

Heterogeneity was assessed using Cochrane's $Q$ and $\mathrm{I}^{2}$-statistics [31]. Heterogeneity was always substantial (I2 >95\%), and so a random-effect models were used. Subgroup analyses was carried out for the three main groups of learning disabilities: Down syndrome, autism and mixed learning disabilities, and estimates compared across subgroups. Although the review protocol stated that the learning disabilities would be grouped depending on the literature, these particular subgroup analyses were exploratory as they had not been specifically planned a priori.

Publication bias was evaluated using Funnel plots as well as Egger's regression intercept test [32]. We assumed asymmetric plots or significant test results $(p<0.05)$ to be an indication for publication bias.

\section{Risk of bias assessment (ROB)}

An adapted Newcastle-Ottawa scale (NOS) [33] was used with a maximum score of ten points (5 for 'Selection', 2 for 'Comparability' and 3 for 'Outcome') spread across seven domains (Additional file 1: Appendix 1): sample representativeness; sample size; non-respondents; ascertainment of data on clinician's decision to intervene at carious lesion thresholds; whether subjects in outcome groups are comparable, based on the study design or analysis, and confounding factors are controlled; assessment of the outcome; and statistical tests. This tool for assessing observational studies such as the ones included in this review has the advantage of allowing the quality of the studies to be compared with those in other reviews as it is commonly used. Scoring was undertaken by two reviewers, with a third 
reviewer resolving any disagreements. Studies were considered at low ROB when the overall scores were 9-10; medium $\mathrm{ROB}$ when scores were 6-8; and high ROB when they were $0-5$.

\section{Results}

\section{Searching/ screening results}

The searches resulted in 995 papers and 869 after deduplication. Following title and abstract screening, 48 full papers were checked and 25 studies found to be eligible for inclusion (Fig. 1). Table 1 shows the excluded studies and the reasons why they were excluded.

\section{Study characteristics}

\section{Study designs and sampling}

Additional file 1: Appendix 2 shows the data tables with all extracted data. The studies were published between 1981 and 2017 with the number of papers published during the past 10 years (16 publications) greater than that number published during the previous three decades (9 publications). All 25 studies were comparative, cross-sectional in design although they varied in how the CLD and CNLD were sampled; in some studies the CNLD were siblings or other family members whereas in others they were sampled from wider representative populations. Where the CNLD were chosen from siblings or matched for age, gender etc. the studies were commonly referred to as case-control or by other terminologies with only five studies $[17,23,28,30,58]$ correctly named as cross-sectional by the authors.

\section{Study settings}

The 25 studies were geographically spread across 18 different countries: one study from each of Argentina [20]; Croatia [59]; Egypt [22]; Finland [60]; Hong Kong [49]; Jordan [15]; Korea [61]; Libya [23]; Sweden [24]; UAE

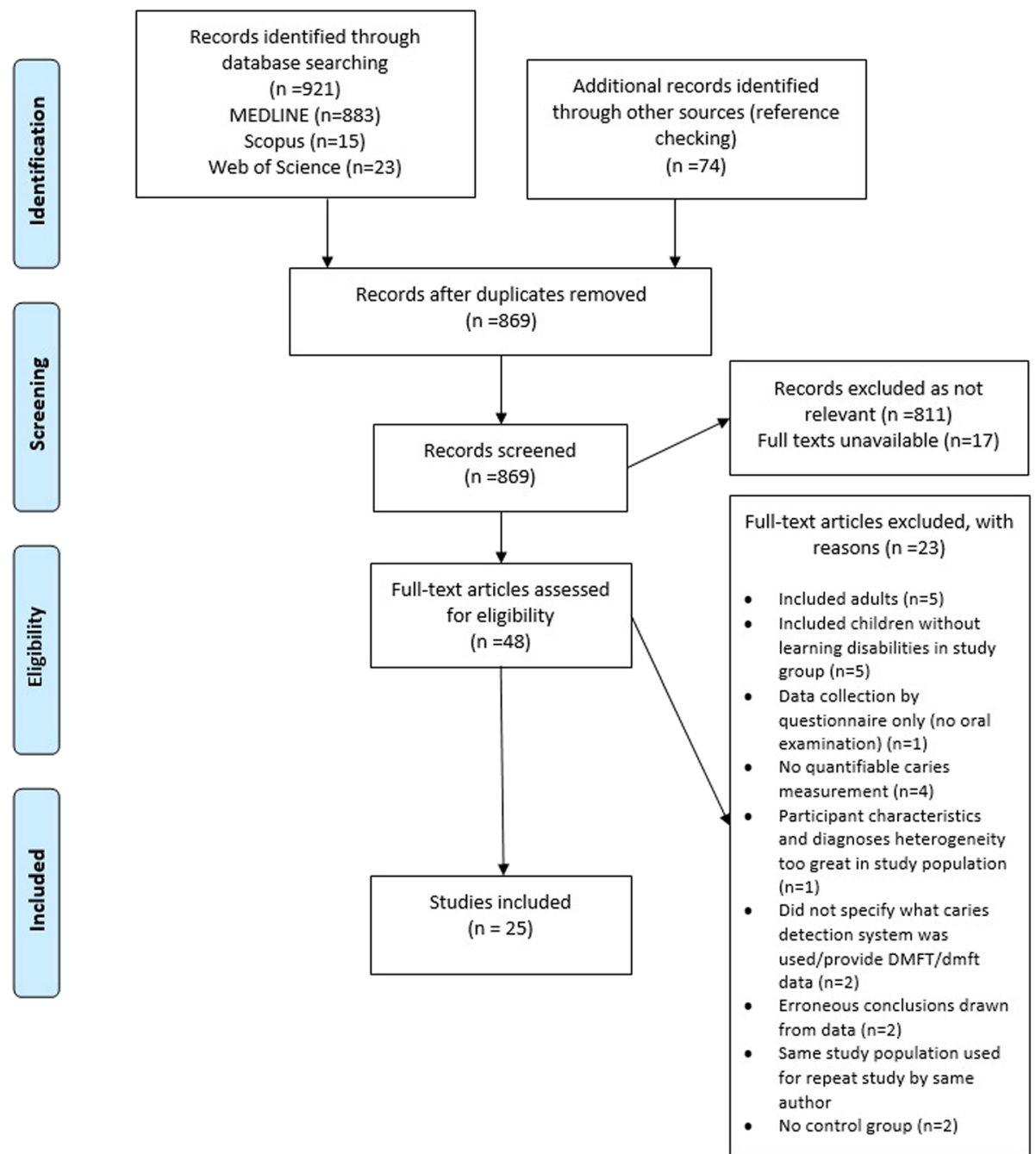

Fig. 1 PRISMA [14] flow diagram of search results and screening of studies with reasons for exclusion and inclusion at full text screening 
Table 1 Full texts obtained and excluded with reason for exclusion ( $n=23$ studies)

\begin{tabular}{|c|c|}
\hline Study & Reason for Exclusion \\
\hline Areias et al., 2011 [34] & No quantifiable measure of DMFT/dmft - descriptive only. \\
\hline Altun et al. 2010 [35] & Included children with physical disabilities as well as learning disabilities and data could not be separated. \\
\hline Areias et al., 2012 [36] & $\begin{array}{l}\text { This seems to be the same group or a repeat study dataset of Areias et al., 2013. This was not clear as it's not } \\
\text { detailed in the paper, but it included the same population of exactly the same age. DMFT and dmft were } \\
\text { different but because of duplicate sampling, even if not the same dataset, we excluded. }\end{array}$ \\
\hline Chadha et al., 2012 [37] & No comparison group \\
\hline Bakarcic et al., 2009 [38] & Not all children in the study population have a learning disability \\
\hline Fahlvik-Planefeldt et al., 2001 [39] & Index for caries recording/detection system not specified, no DMFT/dmft data \\
\hline Fuertes-Gonzales et al., 2014 [40] & This study included adults (age range 2-37 years) and did not allow for extraction of age groups. \\
\hline Fung et al., 2008 [41] & Data collection through questionnaire (no clinical examination carried out) \\
\hline Lowe et al., 1985 [42] & This study included adults (age range 3-30 years) and did not allow for extraction of age groups. \\
\hline Macho et al., 2013 [43] & This study included adults (age range 2-26years) and did not allow for extraction of age groups. \\
\hline Mattila et al., 2001 [44] & No learning disabled children in the study population. \\
\hline Oredugba et al., 2007 [45] & This study included adults and did not allow for extraction of age groups for DMFT/dmft indices \\
\hline Pollard et al., 1992 [46] & No learning disabled children in the study population. \\
\hline Purohit et al., 2010 [47] & Not all children in the study population have a learning disability \\
\hline Radha et al., 2016 [48] & $\begin{array}{l}\text { Errors in study authors' conclusions from dataset: Table } 10 \text { shows CLD to have a lower caries experience than } \\
\text { CNLD group, however the discussion and conclusion sections state the opposite to be true. }\end{array}$ \\
\hline Rai et al., 2012 [50] & Index for caries recording/detection system not specified, no DMFT/dmft data \\
\hline Rekha et al. 2012 [51] & No DMFT/dmft data given, only caries prevalence \\
\hline Ruiz et al., 2018 [52] & This study included adults (age range 4-20 years) and did not allow for extraction of age groups. \\
\hline Sarnat et al., 2016 [53] & Index for caries recording/detection system not specified, no DMFT/dmft data \\
\hline Shaw et al., 1985 [54] & $\begin{array}{l}\text { Dataset includes disabled children from a very wide group also no consistency between children's ages in } \\
\text { the study group and control group. }\end{array}$ \\
\hline Suhaib et al., 2017 [55] & No quantifiable measure of DMFT/dmft - descriptive only. \\
\hline Subramanium et al., 2011 [56] & No comparison group \\
\hline Weckwerth et al., 2016 [57] & $\begin{array}{l}\text { Errors in study authors' conclusions from dataset calculations; Table } 1 \text { demonstrates incorrect results for the } \mathrm{Cl} \\
\text { calculations in the permanent dentition for both groups } 1 \text { and } 2 \text {. }\end{array}$ \\
\hline
\end{tabular}

[26]; UK [62]; Yemen [16]; and Portugal [18]; two conducted in Israel [21, 63], Saudi Arabia [17, 64] and Turkey [58, 65], and three in each of Brazil $[25,27,28]$ and India $[19,29,30]$. The clinical settings ranged from specialist Paediatric dental clinics to school classrooms under natural light (see Additional file 1: Appendix A, B and C).

\section{Disability status and subgrouping}

The disability status of the study participants ranged from single to combined impairments or multiple conditions. Nineteen studies had a main focus on one particular disability, with or without associated impairments. There were two distinct populations included in the studies; children with Downs syndrome ( $n=11$ studies) $[15,17,18,20,21,25,27,29,61,63,65]$ and children with autism ( $n=8$ studies) $[16,19,22,23,26,30,49,58]$. These accounted for over three quarters of the studies (19 out of 25). The remaining six studies focussed on groups of children with non-specific learning disabilities or considered study populations inclusive of a range of learning disability diagnoses $[24,28,59,60,62,64]$. The studies were therefore grouped into those examining children with 1) Down syndrome, 2) autism, and 3) other mixed learning disabilities as per protocol for the subgroup analyses.

\section{Non-participation and representativeness of participating groups}

Across the studies, there tended to be few explicitly stated exclusion criteria. Where stated, children's inability to cooperate, parental refusal, use of orthodontic appliances, systemic disease and absence of valid consent were cited (Additional file 1: Appendix 2). Four studies $[26,29,61,65]$ were more prescriptive in their exclusion criteria; systemic disease, previous disease, medication use, recent local infection and recent dental prophylaxis precluded participation. Eleven studies failed to report any exclusion criteria $[17,20,21,24,27,28,58-60,62,63]$. However, representativeness of the studies was acceptable 
with reasonable overall matching between control group and study group populations by age, gender and socioeconomic status although the number of children in the matched group was sometimes inflated.

\section{Caries assessment; examiners, recording indices and thresholds}

There was no clear description of the person performing the clinical examination in three studies $[18,59,62]$. Data collection was by a single dentist in 17 studies [15, $16,19,20,22,24-27,29,30,49,58,60,61,63,65]$, two dentists in four studies [17, 21, 23, 64] and three dentists in one study [28] and methods varied for assessing and recording caries prevalence; the majority ( $n=16$ studies) used the World Health Organisation (WHO) caries detection system [15-17, 19-23, 26, 28, 29, 49, 58, 63, 65, 66], whilst alternative indices (DMF, NIDR, Rradike $(1972)$ and Moller \& Poulsen) were used in nine others $[18,24,25$, 27, 30, 59-62]. The threshold for caries recording was generally poorly reported and variable where stated. It ranged, for example, from "frank carious cavitation on any surface of any tooth" to "anything beyond a white spot lesion".

\section{Size of participant groups}

Across the studies, the number of participants in the CLD groups ranged from 19 to 257 ( mean $=73$; sd $=47.3$; me$\operatorname{dia} n=62$ ), and from 30 to 301 ( mean $=86$; $\mathrm{sd}=64.6$; median $=70$ ) in the CNLD groups. (Tables 2 and 6). The number of children in the CLD groups was 1819 and in the CNLD was 2157, giving a total of 3976 children included in this review. The sizes of the participant groups by disability subgroup is shown in Tables 3 (Down syndrome), 4 (autism) and 5 (mixed disabilities).

\section{Participant ages}

Participant age ranges were from 1 to 18 years-old (Tables 2, 3, 4, 5, 6, 7, 8 and 9), with two studies [67] reporting subgroups of $\mathrm{dmf} / \mathrm{DMF}$ by age groups (Additional file 1: Appendix 2).

\section{Caries experience in the permanent teeth for CLD compared to CNLD (DMFT)}

Of the 25 studies, 20 reported DMFT, two DMFS [38, 61, 63], one DFS [60], one DFT [64] and one reported on primary teeth only [49] (Additional file 1: Appendix 2 and Tables 2, 3, 4, 5, 6, 7, 8 and 9). For the 20 studies reporting DMFT, eleven included children with Down syndrome $[15,17,18,20,21,25,27,29,61,63,65]$, eight with autism $[16,19,22,23,26,30,49,58]$ and six mixed disability groups $[24,28,59,60,62,64]$. The overall mean DMFT for the CLD was 2.31 (sd \pm 1.97 ; range 0.22 to 7.2 ) and for CNLD was 2.51 (sd \pm 2.14 ; range 0.37 to 4.76). The mean DMFT value for the subgroup of children with Down syndrome was 1.87 (sd \pm 1.08 ; range 0.36 to 3.37) and for the comparison group higher at 2.49 ( $\mathrm{sd} \pm$ 1.42; range 0.4 to 4.59 ) (Table 3). For children with autism (Table 4), the mean DMFT was 1.10 (sd \pm 0.69 ; range 0.22 to 2.00) and 1.01 (sd \pm 0.70 ; range 0.37 to 2.41 ) in the comparison groups. In the four studies with children who had mixed learning disabilities (Table 5) $[24,28,59,62]$ the mean DMFT for CLD was 5.43 (sd \pm 1.85 ; range 2.94 to 7.2) and 5.20 (sd \pm 2.79 ; range 2.27 to 9.0) for CNLD.

There were 16 papers that reported DMFT, where means and variance data were available [15-30]. Heterogeneity in meta-analysis was high $\left(\mathrm{I}^{2}>95 \%\right)$ therefore a random effects meta-analysis was performed. Metaanalysis found no evidence of a difference between the CLD and CNLD for caries experience in the permanent dentition across all disability groups (SMD $=-0.43 ; 95 \%$ $\mathrm{CI}=-0.91$ to 0.05$)$, for children with autism $(\mathrm{SMD}=-0.28$; $95 \% \mathrm{CI}=1.31$ to 0.75$)$ or mixed disabilities $(\mathrm{SMD}=0.26$; $95 \% \mathrm{CI}=-0.94$ to 1.47 ). However, for children with Down syndrome there was a lower caries experience in the CLD compared to the CNLD (SMD $=-0.73 ; 95 \% \mathrm{CI}=-1.28$ to -0.18 ) (Fig. 2). [15-17, 19, 20, 25]

\section{Caries experience in the primary dentition for CLD compared to CNLD (dmft)}

For primary teeth, $\mathrm{dmft} / \mathrm{deft}$ values were reported in nine studies $[16,20,22,23,25,26,30][24,29]$; with

Table 2 DMFT, Care index (CI) and Restorative index (RI) in CLD and CNLD ( $n=25$ studies; 20 studies with DMFT data and 16 with standard deviations reported). Studies where DMFT data couldn't be used are shown in learning disability subgroup tables, with reasons why, but are not included in calculations data couldn't be used are shown, with reasons why, but are not included in calculations. All data were calculated from the primary data reported in Additional file 1: Appendix 2

\begin{tabular}{|c|c|c|c|c|c|c|c|c|c|}
\hline \multicolumn{10}{|c|}{ All learning disability groups ( $n=20$ studies with DMFT data and 16 with SD data) } \\
\hline \multirow[t]{2}{*}{ Study } & \multicolumn{2}{|c|}{ Number of participants } & \multirow[t]{2}{*}{ Ages } & \multicolumn{6}{|c|}{ DMFT data } \\
\hline & CLD & CNLD & & $\begin{array}{l}\text { CLD DMFT } \\
\text { (sd) }\end{array}$ & $\begin{array}{l}\text { CNLD DMFT } \\
\text { (sd) }\end{array}$ & $\mathrm{CLD} \mathrm{Cl}^{\mathrm{a}}$ & $C N L D C^{a}$ & $\left.C L D R\right|^{b}$ & CNLD RI ${ }^{b}$ \\
\hline $\begin{array}{l}\text { Total for all } \\
3 \text { Groups }\end{array}$ & 1819 & 2157 & $1-18$ & & & & & & \\
\hline Mean (sd) & $72.76( \pm 47.31)$ & $86.28( \pm 64.56)$ & & $2.31( \pm 1.97)$ & $2.51( \pm 2.14)$ & $0.12( \pm 0.12)$ & $0.18( \pm 0.27)$ & $0.15( \pm 0.14)$ & $0.28( \pm 0.33)$ \\
\hline
\end{tabular}

abased on 8 studies

b based on 9 studies 
Table 3 DMFT, Care index (Cl) and Restorative index (RI) in CLD and CNLD ( $n=25$ studies; 20 studies with DMFT data and 16 with standard deviations reported). Studies where DMFT data couldn't be used are shown in learning disability subgroup tables, with reasons why, but are not included in calculations data couldn't be used are shown, with reasons why, but are not included in calculations. All data were calculated from the primary data reported in Additional file 1: Appendix 2

\begin{tabular}{|c|c|c|c|c|c|c|c|c|c|c|}
\hline \multicolumn{11}{|c|}{ Down syndrome (permanent teeth; $n=11$ studies) } \\
\hline \multirow[t]{2}{*}{ Study } & \multicolumn{2}{|c|}{ Number of participants } & \multirow[t]{2}{*}{ Ages } & \multicolumn{7}{|l|}{ DMFT data } \\
\hline & CLD & CNLD & & $\begin{array}{l}\text { CLD DMFT } \\
(\mathrm{sd})\end{array}$ & $\begin{array}{l}\text { CNLD DMFT } \\
\text { (sd) }\end{array}$ & $\mathrm{CLD} \mathrm{Cl}$ & CND Cl & CLD RI & CNLD RI & $\begin{array}{l}\text { Reason no DMFT } \\
\text { data included }\end{array}$ \\
\hline $\begin{array}{l}\text { Al Habashneh } 2012 \\
\text { [15] }\end{array}$ & 103 & 103 & $12-16$ & $3.32(3.77)$ & $4.59(4.21)$ & & & & & \\
\hline AlSarheed 2015 [17] & 93 & 99 & $7-15$ & $2.66(3.09)$ & $3.11(2.58)$ & 0.18 & 0.18 & 0.22 & 0.19 & \\
\hline Areias 2013 [18] & 45 & 45 & $6-18$ & $1.02(2.42)$ & $1.84(3.13)$ & 0.16 & 0.02 & 0.27 & 0.04 & \\
\hline Cogulu 2006 [65] & 73 & 70 & $7-12$ & 0.92 & 4.26 & & & & & \\
\hline Cornejo $1996[20,67]$ & 86 & 86 & $10-13$ & $1.30(0.30)$ & $1.70(0.40)$ & & & & & \\
\hline Davidovich 2010 [21] & 70 & 32 & $1-9$ & $3.37(0.56)$ & $5.90(0.8)$ & & & & & \\
\hline Hashizume 2017 [25] & 61 & 52 & $6-14$ & $0.36(1.00)$ & $0.40(0.92)$ & & & & & \\
\hline Lee 2004 [61] & 19 & 41 & $8-17$ & & & & & & & DMFS only \\
\hline Mathias 2011 [27] & 69 & 69 & $1-7$ & $2.20(6.30)$ & $3.40(8.10)$ & & & & & \\
\hline Stabholz 1991 [63] & 32 & 30 & $8-13$ & & & & & & & DMFS only \\
\hline Subramaniam 2014 [29] & 34 & 34 & $7-12$ & $1.68(0.69)$ & $1.84(1.12)$ & & & & & \\
\hline Subgroup Total & 685 & 661 & & & & & & & & \\
\hline Mean (sd) & $62.27( \pm 26.97)$ & $60.09( \pm 26.90)$ & & $1.87( \pm 1.08)$ & $2.49( \pm 1.42)$ & & & & & \\
\hline
\end{tabular}

a mean $\mathrm{dmft} / \mathrm{deft}$ of 2.24 for CLD and 2.48 for CNLD. Two studies only reported dft values $[59,66]$ (Additional file 1: Appendix 2).

For the three studies with children who had Down syndrome [20, 25, 29], the mean $\mathrm{dmft} / \mathrm{deft}$ was 2.31 (sd \pm 0.43 ; range 1.84 to 2.69 ) for CLD and 1.86 ( $\mathrm{sd} \pm 0.97$; range 0.98 to 2.90) for CNLD with two of the three studies finding the dmft to be higher for the CLD,

There were five studies on autism [16, 22, 23, 26, 30] . The mean $\mathrm{dmft} / \mathrm{deft}$ was 2.42 ( $\mathrm{sd} \pm 1.90$; range 0.80 to 5.23) for CLD and 2.27 (sd \pm 1.73 ; range 0.30 to 4.06 ) for CNLD. Three studies reported children with autism to

Table 4 DMFT, Care index (Cl) and Restorative index (RI) in CLD and CNLD ( $n=25$ studies; 20 studies with DMFT data and 16 with standard deviations reported). Studies where DMFT data couldn't be used are shown in learning disability subgroup tables, with reasons why, but are not included in calculations data couldn't be used are shown, with reasons why, but are not included in calculations. All data were calculated from the primary data reported in Additional file 1: Appendix 2

\begin{tabular}{|c|c|c|c|c|c|c|c|c|c|c|}
\hline \multicolumn{11}{|c|}{ Autism (permanent teeth; $n=8$ studies) } \\
\hline \multirow[t]{2}{*}{ Study } & \multicolumn{2}{|c|}{ Number of participants } & \multirow[t]{2}{*}{ Ages } & \multicolumn{7}{|l|}{ DMFT data } \\
\hline & CLD & CNLD & & $\begin{array}{l}\text { CLD DMFT } \\
\text { (sd) }\end{array}$ & $\begin{array}{l}\text { CNLD DMFT } \\
\text { (sd) }\end{array}$ & CLD Cl & CNLD Cl & CLD RI & CNLD Rl & $\begin{array}{l}\text { Reason no DMFT } \\
\text { data included }\end{array}$ \\
\hline Al-Maweri 2014 [16] & 42 & 84 & $5-16$ & $2.00(2.18)$ & $1.27(1.77)$ & 0 & 0.02 & 0.04 & 0.03 & \\
\hline Bhandary 2017 [19] & 30 & 30 & $6-12$ & $0.37(0.62)$ & $0.37(0.56)$ & 0 & 0.19 & 0 & 0.35 & \\
\hline Du 2014 [49] & 257 & 257 & $3-7$ & & & 0.10 & 0.09 & 0.11 & 0.09 & dmfs only \\
\hline $\begin{array}{l}\text { El Khatib } 2014 \\
\text { [22] }\end{array}$ & 100 & 100 & $3-13$ & $3.40(4.54)$ & $3.50(3.63)$ & & & & & \\
\hline Fakroon 2014 [23] & 50 & 50 & $3-14$ & $0.22(0.08)$ & $1.15(0.27)$ & 0.1 & 0.06 & 0.1 & 0.07 & \\
\hline Jaber 2011 [26] & 61 & 61 & $6-16$ & $1.60(0.64)$ & $0.60(0.29)$ & & & & & \\
\hline Namal 2007 [58] & 62 & 301 & $7-12$ & 1.74 & 2.41 & 0.04 & 0.06 & 0.05 & 0.06 & \\
\hline Yashoda 2014 [30] & 135 & 135 & $4-15$ & $0.86(1.22)$ & $0.46(1.06)$ & & & & & \\
\hline Subgroup Total & 737 & 1018 & & & & & & & & \\
\hline Mean (sd) & $92.13( \pm 74.74)$ & $127.25( \pm 99.65)$ & & $1.10( \pm 0.69)$ & $1.01( \pm 0.70)$ & & & & & \\
\hline
\end{tabular}


Table 5 DMFT, Care index (Cl) and Restorative index (RI) in CLD and CNLD ( $n=25$ studies; 20 studies with DMFT data and 16 with standard deviations reported). Studies where DMFT data couldn't be used are shown in learning disability subgroup tables, with reasons why, but are not included in calculations data couldn't be used are shown, with reasons why, but are not included in calculations. All data were calculated from the primary data reported in Additional file 1: Appendix 2

\begin{tabular}{|c|c|c|c|c|c|c|c|c|c|c|}
\hline \multicolumn{11}{|c|}{ Mixed Learning Disability Groups (permanent teeth; $n=6$ studies) } \\
\hline \multirow[t]{2}{*}{ Study } & \multicolumn{2}{|c|}{ Number of participants } & \multirow[t]{2}{*}{ Ages } & \multicolumn{7}{|l|}{ DMFT data } \\
\hline & CLD & CNLD & & $\begin{array}{l}\text { CLD DMFT } \\
\text { (sd) }\end{array}$ & $\begin{array}{l}\text { CNLD DMFT } \\
(\mathrm{sd})\end{array}$ & $\mathrm{CLD} \mathrm{Cl}$ & CND Cl & CLD Rl & CNLD RI & $\begin{array}{l}\text { Reason no DMFT } \\
\text { data included }\end{array}$ \\
\hline Bakry $2012[64,66]$ & 33 & 53 & $3-13$ & & & & & 0.12 & 0.84 & DFT only \\
\hline $\begin{array}{l}\text { Forsberg } \\
1985 \text { [24] }\end{array}$ & 100 & 103 & $12-17$ & $7.20(6.10)$ & $9.00(4.00)$ & & & & & \\
\hline Jokic 2007 [59] & 80 & 80 & $3-17$ & 6.39 & 4.76 & & & & & \\
\hline Moreira 2012 [28] & 76 & 89 & mean 8.9 & $5.20(5.75)$ & $1.50(2.10)$ & & & & & \\
\hline Palin 1982 [60] & 58 & 58 & $9-10$ & & & & & & & no $M$ or DMFS \\
\hline Pope 1991 [62] & 50 & 95 & $3-18$ & 2.94 & 2.27 & 0.36 & 0.82 & 0.43 & 0.82 & \\
\hline Subgroup Total & 397 & 478 & & & & & & & & \\
\hline Mean (sd) & $66.17( \pm 23.92)$ & $79.67( \pm 20.24)$ & & $5.43( \pm 1.85)$ & $5.20( \pm 2.79)$ & & & & & \\
\hline
\end{tabular}

have a higher caries experience than children without autism [16, 26, 30].

The study of deft for children with other disabilities [24] found a deft of 2.00 for CLD and 3.30 for CNLD.

There were eight papers $[16,20,22,23,25,26,29,30]$ that reported means and variance for dmft (Fig. 3). Metaanalyses found no evidence of a difference between the CLD and CNLD for caries experience across all disability groups (SMD $=0.41 ; 95 \% \mathrm{CI}=-0.14$ to 0.96 ), for children with Down syndrome $(\mathrm{SMD}=0.55 ; 95 \% \mathrm{CI}=-0.40$ to 1.52 ), autism (SMD $=0.43 ; 95 \% \mathrm{CI}=-0.53$ to 2.39 ) or mixed disabilities (SMD $=-0.10 ; 95 \% \mathrm{CI}=-0.34$ to 0.14 ).

\section{Care, and restorative indices (permanent teeth)}

There were eight studies [16-19, 23, 49, 58, 62] that stated the CI and RI or had data (decayed, missing and filled teeth values) that allowed calculation of both and one stated only the RI [64]. In five of eight studies, the CI for CLD was less than or equal to CNLD [16, 17, 19, 58, 62]. The RI for the permanent dentition was available for nine studies [16-19, 23, 26, 49, 58, 62, 64]. The RI for CLD was less than or equal to CNLD in four $[19,58,62,66]$ of the nine studies where it was available $[16-19,23,26,49,58$, $62,64]$. Meta-analysis was not possible on the data as there were no variance data given for any studies.

\section{Care index and restorative index (primary teeth)}

Two studies, both on children with autism, allowed calculation of the $\mathrm{CI}$ in the primary dentition [16, 23]. One [16] found it to be higher in CNLD, whilst the other [23] found it to be higher in CLD. Similarly, the two studies where calculation of the RI was possible reported conflicting findings; Bakry et al. (2012) found the RI to be higher in CLD whilst Fakroon et al. [23] found it to be higher in CNLD.

\section{Narrative reports of unmet dental need}

An additional six papers [26, 67-69] gave narrative reports on levels of unmet dental need and common treatment modalities (Table 10). Five of the six studies [26, 67,69 ] noted a greater unmet treatment need in the CLD population although there were no numerical data to verify these statements.

Table $6 \mathrm{dmft}$, Care index (Cl) and Restorative index (RI) in CLD and CNLD ( $n=25$ studies; 9 studies with dmft and standard deviations reported). All learning disability groups. Studies where dmft data couldn't be used are shown in learning disability subgroup tables, with reasons why, but are not included in calculations. All data were calculated from the primary data reported in Additional file 1: Appendix 2

\begin{tabular}{|c|c|c|c|c|c|c|c|c|c|}
\hline \multicolumn{10}{|c|}{ All learning disability subgroups (primary teeth; $n=9$ studies with dmft data) } \\
\hline \multirow[t]{2}{*}{ Study } & \multicolumn{2}{|c|}{ Number of participants } & \multirow[t]{2}{*}{ Ages } & \multicolumn{6}{|c|}{$\mathrm{dmft} /$ deft data } \\
\hline & $\mathrm{CLD}$ & CNLD & & $\begin{array}{l}\text { CLD dmft / } \\
\text { deft (sd) }\end{array}$ & $\begin{array}{l}\text { CNLD dmft / } \\
\text { deft (sd) }\end{array}$ & $\mathrm{CLD} \mathrm{Cl}^{\mathrm{a}}(\mathrm{sd})$ & $C N L D C l^{a}(s d)$ & $\mathrm{CLD} \mathrm{RI}^{\mathrm{a}}(\mathrm{sd})$ & CNLD Rl ${ }^{a}(\mathrm{sd})$ \\
\hline $\begin{array}{l}\text { Total for all } \\
3 \text { Groups }\end{array}$ & 1819 & 2157 & & & & & & & \\
\hline Mean (sd) & $72.76( \pm 47.31)$ & $86.28( \pm 64.56)$ & & $2.34( \pm 1.37)$ & $2.25( \pm 1.39)$ & $0.15( \pm 0.14)$ & $0.06(0.06)$ & $0.15( \pm 0.14)$ & $0.04( \pm 0.01)$ \\
\hline
\end{tabular}

${ }^{\mathrm{a}}$ based on 2 studies 
Table $7 \mathrm{dmft}$, Care index (CI) and Restorative index (RI) in CLD and CNLD ( $n=25$ studies; 9 studies with dmft and standard deviations reported). Down syndrome subgroup. Studies where dmft data couldn't be used are shown in learning disability subgroup tables, with reasons why, but are not included in calculations. All data were calculated from the primary data reported in Additional file 1: Appendix 2

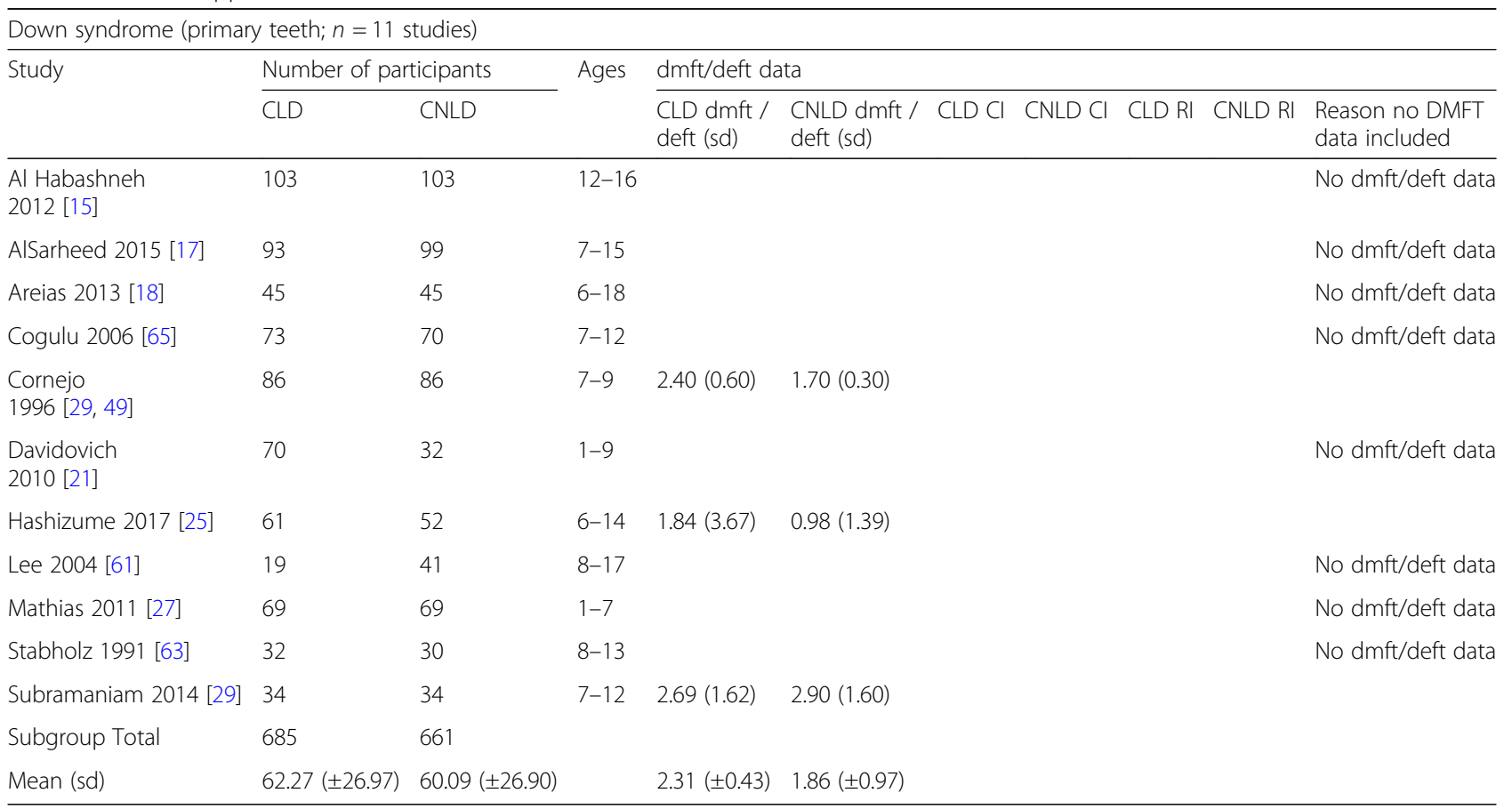

Table $8 \mathrm{dmft}$, Care index (Cl) and Restorative index (RI) in CLD and CNLD ( $\mathrm{n}=25$ studies; 9 studies with dmft and standard deviations reported). Autism subgroup. Studies where dmft data couldn't be used are shown in learning disability subgroup tables, with reasons why, but are not included in calculations. All data were calculated from the primary data reported in Additional file 1: Appendix 2

\begin{tabular}{|c|c|c|c|c|c|c|c|c|c|c|}
\hline \multicolumn{11}{|c|}{ Autism (primary teeth; $n=8$ studies) } \\
\hline \multirow[t]{2}{*}{ Study } & \multicolumn{2}{|c|}{ Number of participants } & \multirow[t]{2}{*}{ Ages } & \multicolumn{7}{|c|}{ dmft/deft data } \\
\hline & CLD & CNLD & & $\begin{array}{l}\text { CLD dmft / } \\
\text { deft (sd) }\end{array}$ & $\begin{array}{l}\text { CNLD dmft / } \\
\text { deft (sd) }\end{array}$ & $\mathrm{CLD} \mathrm{Cl}$ & CNLD Cl & CLD RI & CNLD RI & $\begin{array}{l}\text { Reason no DMFT } \\
\text { data included }\end{array}$ \\
\hline $\begin{array}{l}\text { Al-Maweri } \\
2014 \text { [16] }\end{array}$ & 42 & 84 & $5-16$ & $5.23(2.34)$ & $4.06(2.98)$ & 0.05 & 0.10 & & & \\
\hline $\begin{array}{l}\text { Bhandary } \\
2017 \text { [19] }\end{array}$ & 30 & 30 & $6-12$ & & & & & & & No dmft/deft data \\
\hline Du 2014 [49] & 257 & 257 & $3-7$ & & & & & & & No dmft/deft data \\
\hline $\begin{array}{l}\text { El Khatib } \\
2014 \text { [22] }\end{array}$ & 100 & 100 & $3-13$ & $3.53(4.57)$ & $3.56(3.86)$ & & & & & \\
\hline Fakroon 2014 [23] & 50 & 50 & $3-14$ & $1.13(1.84)$ & $2.85(3.32)$ & 0.25 & 0.02 & 0.25 & 0.03 & \\
\hline Jaber 2011 [26] & 61 & 61 & $6-16$ & $0.80(0.20)$ & $0.30(0.30)$ & & & & & \\
\hline Namal 2007 [58] & 62 & 301 & $7-12$ & & & & & & & No dmft/deft data \\
\hline $\begin{array}{l}\text { Yashoda } \\
2014 \text { [30] }\end{array}$ & 135 & 135 & $4-15$ & $0.40(2.48)$ & $0.59(1.28)$ & & & & & \\
\hline Subgroup Total & 737 & 1018 & & & & & & & & \\
\hline Mean (sd) & $92.13( \pm 74.74)$ & $127.25( \pm 99.65)$ & & $2.42( \pm 1.90)$ & $2.27( \pm 1.73)$ & & & & & \\
\hline
\end{tabular}


Table $9 \mathrm{dmft}$, Care index $(\mathrm{Cl})$ and Restorative index (RI) in CLD and CNLD ( $n=25$ studies; 9 studies with dmft and standard deviations reported). Mixed learning disabilities subgroup. Studies where dmft data couldn't be used are shown in learning disability subgroup tables, with reasons why, but are not included in calculations. All data were calculated from the primary data reported in Additional file 1: Appendix 2

\begin{tabular}{|c|c|c|c|c|c|c|c|c|c|}
\hline \multicolumn{10}{|c|}{ Mixed Learning Disability Groups (primary teeth; $n=6$ studies) } \\
\hline \multirow[t]{2}{*}{ Study } & \multicolumn{2}{|c|}{ Number of participants } & \multirow[t]{2}{*}{ Ages } & \multicolumn{6}{|c|}{ dmft/deft data } \\
\hline & CLD & CNLD & & $\begin{array}{l}\text { CLD dmft / } \\
\text { deft (sd) }\end{array}$ & $\begin{array}{l}\text { CNLD dmft / CLD Cl } \\
\text { deft (sd) }\end{array}$ & CNLD Cl & CLD Rl & CNLD RI & $\begin{array}{l}\text { Reason no DMFT } \\
\text { data included }\end{array}$ \\
\hline $\begin{array}{l}\text { Bakry } 2012 \\
{[64,66]}\end{array}$ & 33 & 53 & $3-13$ & & & & 0.05 & 0.04 & No dmft/deft data \\
\hline $\begin{array}{l}\text { Forsberg } \\
1985[24]\end{array}$ & 100 & 103 & $3-11$ & $2.00(2.90)$ & $3.30(2.80)$ & & & & \\
\hline Jokic 2007 [59] & 80 & 80 & $3-17$ & & & & & & No dmft/deft data \\
\hline Moreina 2012 [28] & 76 & 89 & mean 8.9 & & & & & & No dmft/deft data \\
\hline Palin 1982 [60] & 58 & 58 & $9-10$ & & & & & & No dmft/deft data \\
\hline Pope 1991 [62] & 50 & 95 & $3-18$ & & & & & & No dmft/deft data \\
\hline Subgroup Total & 397 & 478 & & & & & & & \\
\hline Mean (sd) & $66.17( \pm 23.92)$ & $79.67( \pm 20.24)$ & & 2.00 & 3.30 & & & & \\
\hline
\end{tabular}

\section{Quality assessment}

Intra-study $\mathrm{ROB}$ ranged from 2 to 9 , with a mean score of 5.2 showing a generally medium to high risk of bias across the studies. One study only scored two points out of the 10 possible [59]. Each study could be awarded a maximum score of 10 points across three domains. The mean scores across each domain were: 1.6 out of a possible score of 2 points for 'comparability'; 1.9 out of 5 for 'selection'; and 1.6 out of 3 for 'outcome'. Five studies described the sample size calculations $[19,28,70]$.

Of the 25 studies in the systematic review, the breakdown of quality assessment scoring, as per the Newcastle-Ottawa Scale (NOS) was as follows (see

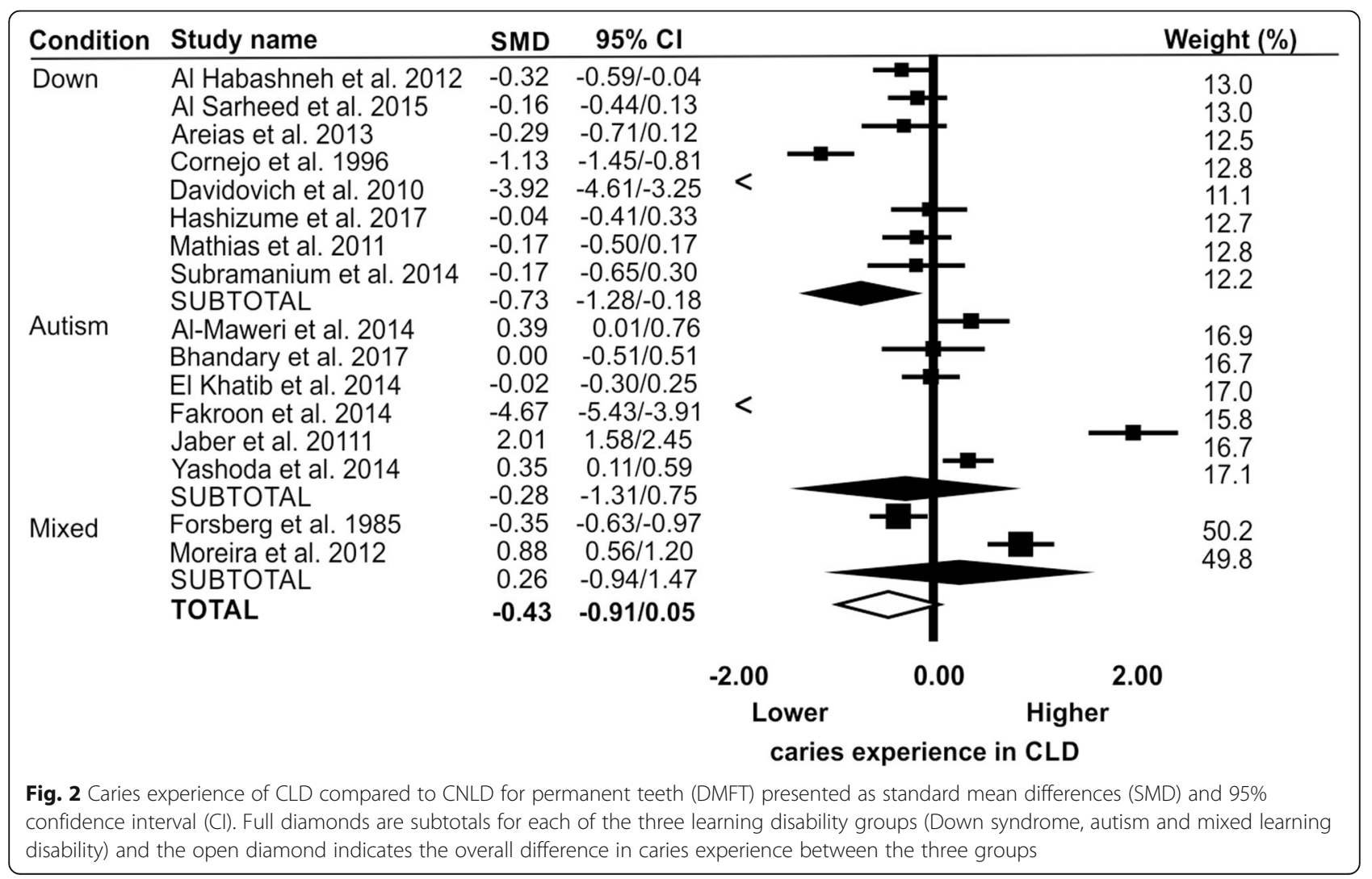




\begin{tabular}{|c|c|c|c|c|}
\hline Condition & Study name & SMD & $95 \% \mathrm{Cl}$ & Weight (\%) \\
\hline \multirow[t]{4}{*}{ Down } & Cornejo et al. 1996 & 1.48 & $1.14 / 1.81$ & 33.9 \\
\hline & Hashizume et al. 2017 & 0.30 & $-0.08 / 0.67$ & 33.6 \\
\hline & Subramanium et al. 2014 & -0.13 & $-0.61 / 0.35$ & 32.5 \\
\hline & SUBTOTAL & 0.55 & $-0.40 / 1.52$ & \\
\hline \multirow[t]{5}{*}{ Autism } & Al-Maweri et al. 2014 & 0.42 & $0.05 / 0.79$ & 25.0 \\
\hline & El Khatib et al. 2014 & 0.00 & $-0.28 / 0.27$ & 25.4 \\
\hline & Fakroon et al. 2014 & -0.64 & $-1.04 /-0.23$ & 24.9 \\
\hline & Jaber et al. 2014 & 1.96 & $1.53 / 2.39$ & 24.7 \\
\hline & SUBTOTAL & 0.43 & $-0.53 / 1.39$ & \\
\hline \multirow[t]{6}{*}{ Mixed } & Yashoda et al. 2011 & -0.10 & $-0.34 / 0.14$ & 100.0 \\
\hline & SUBTOTAL & -0.10 & $-0.34 / 0.14$ & \\
\hline & TOTAL & 0.41 & $-0.14 / 0.96$ & \\
\hline & & & -2.00 & 2.00 \\
\hline & & & Lower & Higher \\
\hline & & \multicolumn{3}{|c|}{ caries experience in CLD } \\
\hline \multicolumn{5}{|c|}{$\begin{array}{l}\text { Fig. } 3 \text { Caries experience of CLD compared to CNLD for primary teeth (dmft) presented as standard mean differences (SMD) and 95\% confidence } \\
\text { interval (CI). Full diamonds are subtotals for each of the three learning disability groups (Down syndrome, autism and mixed learning disability) } \\
\text { and the open diamond indicates the overall level of caries experience between the two groups }\end{array}$} \\
\hline
\end{tabular}

Additional file 1: Appendices 3A, 3B and 3C for full details):

- High quality (scoring 9-10 out of 10 across the three domains) $n=1$ [23];

- medium quality (scoring 6-8 out of 10 across the three domains) $n=9[15-17,22,29,49,60,65,66]$; and

- low quality (scoring $0-5$ out of 10 across the three domains) $n=15[18-21,24-28,30,58,59$, 61-63].

\section{Assessment of publication bias}

There was no evidence of publication bias from the symmetry of the Funnel plots or Egger's regression intercept test (Fig. 4a and b).

\section{Discussion}

There is a lack of evidence around the impact that disability has on oral health and oral healthcare experience for children $[10,11]$. This systematic review found 25 comparative, cross-sectional studies set in 18 countries including 3976 children (CLD 1819; CNLD 2157). This

Table 10 Included studies with descriptions of levels of unmet dental need where these were reported narratively but without supporting numerical data

\begin{tabular}{|c|c|c|c|}
\hline Study & Disability for CLD group & $\begin{array}{l}\text { Relative level of unmet dental need } \\
\text { in CLD compared with CNLD }\end{array}$ & Narrative text on dental care provided for caries \\
\hline Cornejo $1996[29,49]$ & Down & Higher for CLD & $\begin{array}{l}\text { DS children receive less treatment of the deciduous } \\
\text { dentition - this may be due to the delay in eruption } \\
\text { of the teeth when examined alongside non-DS } \\
\text { children of a similar age. }\end{array}$ \\
\hline El Khatib 2014 [22] & Autism & Higher for CLD & $\begin{array}{l}\text { In the primary dentition, children with ASD had more } \\
\text { untreated caries. In the mixed stage, ASD children with } \\
\text { ASD had less filled teeth than children without ASD. }\end{array}$ \\
\hline Jaber 2011 [26] & Autism & Higher for CLD & Autistic children receive $60 \%$ less treatment. \\
\hline Palin 1982 [60] & Range of conditions & Higher for CLD & $\begin{array}{l}\text { In comparison with the healthy, the retarded children } \\
\text { are not given enough dental care with respect to their } \\
\text { treatment need. }\end{array}$ \\
\hline Stabholz 1991 [63] & Down & Higher for CLD & $\begin{array}{l}\text { Authors hypothesise that because treating those with } \\
\text { DS and MR (institutionalised) is more expensive, more } \\
\text { complex and requires more specialised personnel, only } \\
\text { a small proportion of their needs are met. }\end{array}$ \\
\hline Forsberg 1985 [24] & Range of conditions & Lower for CLD & $\begin{array}{l}\text { The severely mentally retarded children had been offered } \\
\text { dental care to the same extent as healthy children }\end{array}$ \\
\hline
\end{tabular}



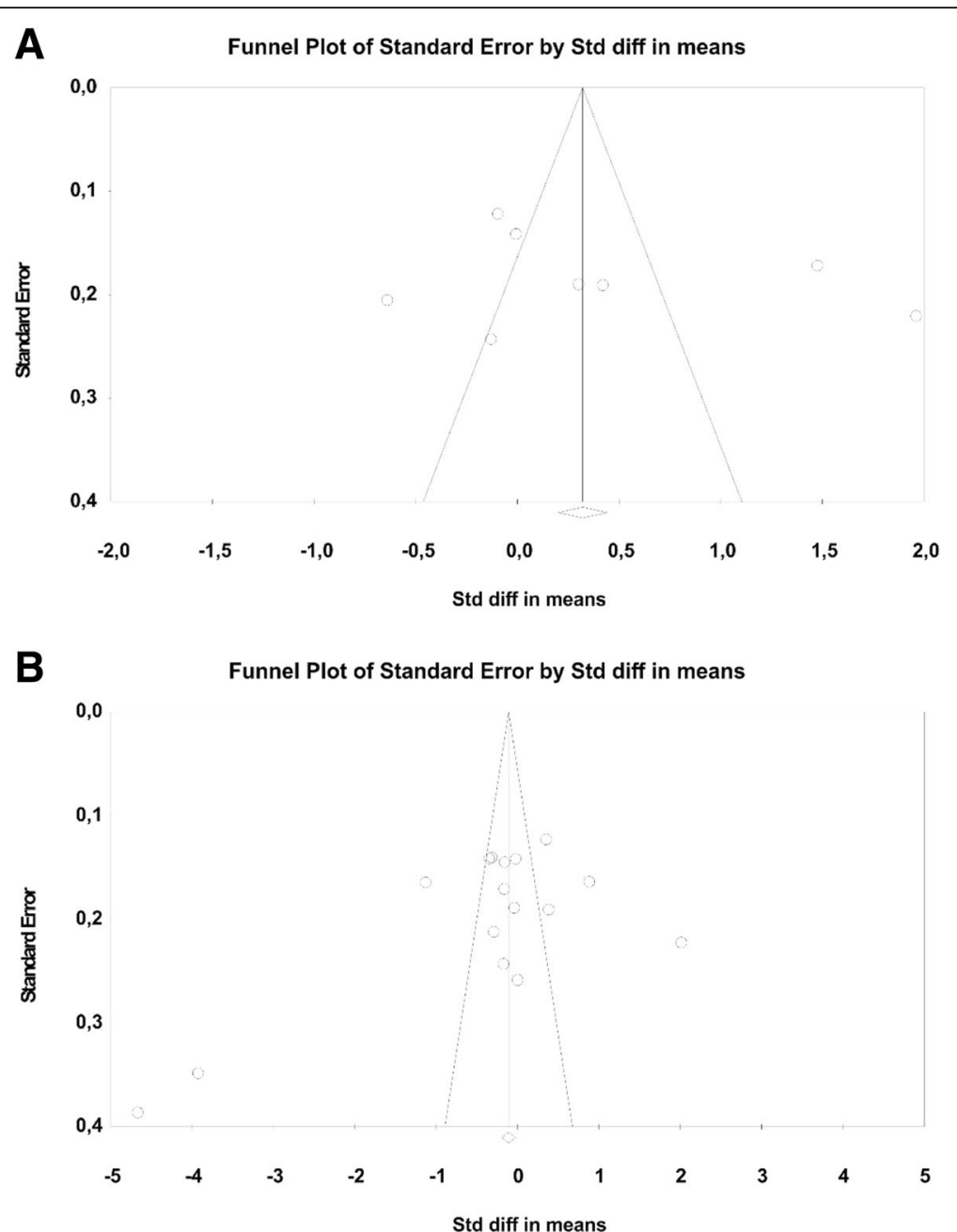

Fig. 4 a Funnel plot to investigate publication bias in permanent dentition. b Funnel plot to investigate publication bias in primary dentition

seems to be an area of growing interest, with almost twice as many publications in the last 10 years than in the previous 30 years. None of the recent three systematic reviews $[10,11]$ in this area seemed to find all of the papers we included. However, we involved an information technologist to help find the correct terms and papers and it was noted that research in this area is very poorly "tagged" in electronic literature databases with a lack of standardised keywords and therefore is difficult to find.

The two main groups of children with learning disabilities that were investigated were those with Down syndrome and those with autism, comprising three quarters of the sample of studies. The other group that seems to be of interest are children with cerebral palsy. However, reporting characteristics of children with cerebral palsy in these studies were poor, with very few specifying whether the children had any learning disability. As this is not one of the defining features of cerebral palsy [71] we only included studies where there was explicit information on the inclusion of children with learning disabilities.

Meta-analyses between studies allows pooled estimates using weighted averages for different studies. This method of data aggregation gives greater statistical power, more precise point estimates and the ability to look for patterns in results, for example through subgroup analyses. However, its correct use relies partly on appropriate assumptions being made about the similarity of studies. There were a number differences between the studies encompassed in this review including: comparison groups (some studies chose siblings of similar ages, others matched the CLD group with children from the general population of same gender and age); age groups included; type of learning disability; and the carious lesion diagnostic threshold (although this was not consistently well reported). However, we considered that there was enough homogeneity across the samples and similarities between the groups to be able to carry out metaanalyses. 
For permanent teeth, meta-analysis included 16 out of the 20 studies where DMFT was available. It showed no evidence of a difference between CLD and CNLD for caries experience (SMD:-0.43; 95\% CI:-0.91 to 0.05) or for subgroup analyses by disability for children with autism ( $\mathrm{SMD}=-0.28 ; 95 \% \mathrm{CI}=1.31$ to 0.75$)$ and mixed disabilities $(\mathrm{SMD}=0.26 ; 95 \% \mathrm{CI}=-0.94$ to 1.47$)$. However, for children with Down syndrome caries experience was lower for CLD than CNLD (SMD $=-0.73 ; 95 \% \mathrm{CI}=-1.28$ to -0.18 ).

For primary teeth, meta-analysis could be carried out, with eight studies and showed no evidence of a difference between CLD and CNLD for caries experience across disability groups $(\mathrm{SMD}=0.41 ; 95 \% \mathrm{CI}=-0.14$ to $0.96)$ or in sub-group analyses by disability group: Down syndrome $(\mathrm{SMD}=0.55 ; 95 \% \mathrm{CI}=-0.40$ to 1.52$)$, autism ( $\mathrm{SMD}=0.43 ; 95 \% \mathrm{CI}=-0.53$ to 2.39$)$ and mixed disabilities $(\mathrm{SMD}=-0.10 ; 95 \% \mathrm{CI}=-0.34$ to 0.14$)$.

There is some disagreement in the literature around whether those with Down syndrome experience less caries than the general population however a recent systematic review [10] found no evidence that people with Down syndrome have a lower experience of dental caries than nonsyndromic individuals. Key features of Down syndrome such as hypodontia and microdontia have been suggested as possible factors contributing to this (by making proximal surfaces accessible to saliva and toothpaste). However, there has also been quite extensive investigation of biological factors that convey some protection such as salivary secretory IgA $[61,65]$. One of the complicating factors in trying to interpret data for Down syndrome children and caries experience is the delay in tooth eruption which might also convey some protection. In one study where the delay in tooth eruption was taken into consideration, the caries experience of those participants with Down syndrome compared to non-syndromic individuals became not significant [72]. This suggests that studies investigating caries experience in people with Down syndrome should take into consideration timing of tooth eruption and not just participant ages.

As well as looking at levels of dental caries, our aspiration with this paper had been to look at levels and type of dental care provision using the care- and restorativeindices [73]. However, although there were mean values for eight studies for the CI and in nine studies for the RI, there were no standard deviations to show variance around the means for any of the studies. This meant that no meta-analyses could be carried out for permanent teeth. The mean CI (CLD: $0.12 \pm 0.12$; CNLD: $0.18 \pm$ 0.27 ) and RI (CLD: $0.18 \pm 0.27$; CNLD: $0.28 \pm 0.33$ ) values showed a greater difference between the $\mathrm{CI}$ and RI for the CNLD than CLD (although it should be noted that the standard deviations are large). Only three studies provided CI and/or RI data for primary teeth and these showed mixed results regarding the quantity of care provided, and the nature of the interventions therefore no conclusions could be drawn [16, 23, 64].

Missing teeth are not included in the RI but are included in the CI formula; the higher the number of missing/ extracted teeth compared to restored teeth, the greater the difference between the CI and the RI as illustrated in Fig. 5.

For the permanent dentition the $\mathrm{CI}$ and RI values for CNLD were similar, whereas for CLD the RI tended to
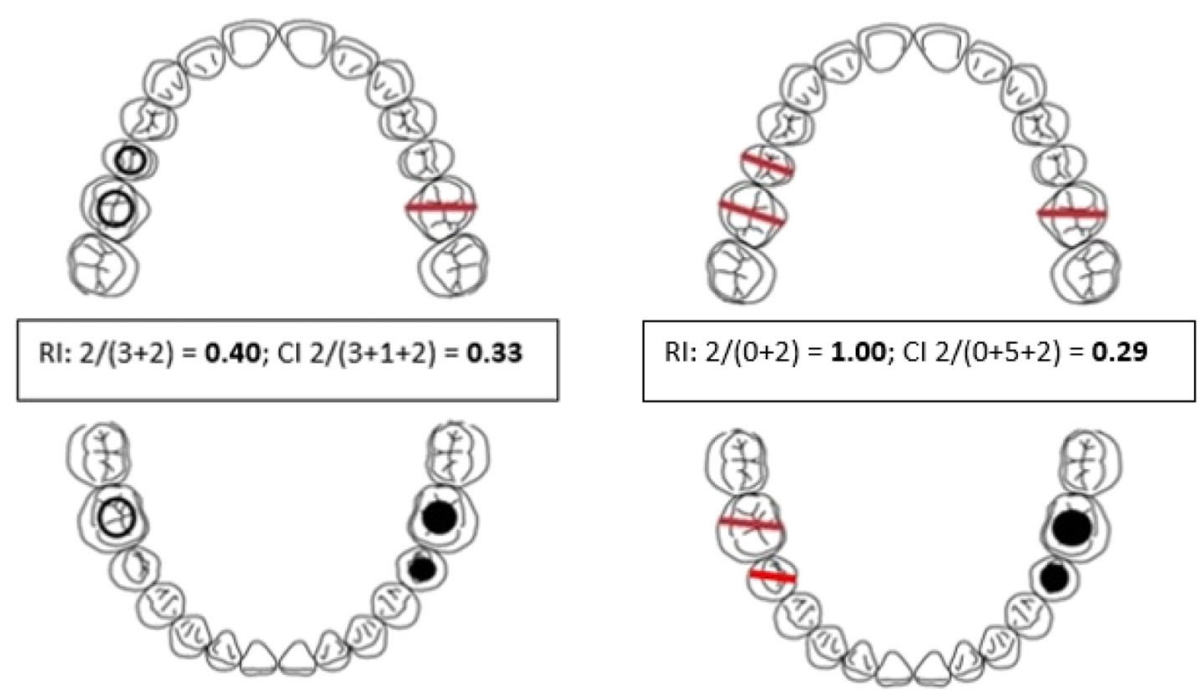

Fig. 5 Diagrammatic representation of differences in $\mathrm{Cl}$ and Rl. There are two individuals with similar caries experience, the $\mathrm{Cl}$ is similar for both ( 0.33 and 0.29 ) but the Rl is only 0.4 for the one who has had less restorative care and reaches 1.00 for the one who has had additional carious teeth extracted rather than left carious. This shows that the greater the difference between the $\mathrm{Cl}$ and $\mathrm{Rl}$, the more extraction based treatment has been used rather than restorative based treatment to manage carious teeth 
be higher than the CI (Table 2). This means that there are more teeth being extracted than restored in the CLD to manage their carious teeth.

This was corroborated by five of the six papers that narratively (but with no quantitative data) reported on the levels and types of dental care for CLD (Table 10). This data was not in the original protocol or inclusion criteria and was extracted post-hoc. Whilst this means that some studies with narrative information on levels and types of dental care provision may not have been included, this kind of data is likely to only have been found in papers that quantitatively analysed caries rates and this was an inclusion criterion. This means that there was a low risk of studies including this narrative information not being found during the search and included. Whether data is quantitative or narrative, there are four areas to consider in making judgements on data synthesis: 1) the direction of the effect 2) the size of any effect 3) consistency across studies and 4) strength of evidence [74]. There was sparse data available from the included studies quantitatively through the CI and RI (limited by the lack of variance data) and narratively through the descriptions of amount and type of dental care provided in CLD. However, the consistency of data - that there seemed to be a tendency for extraction based care over restorative based care - indicates a need for further research on this topic to ensure service is being tailored to those who need it. Poor reporting of research, making it not possible to use collected data in secondary analyses, is indicative of a much wider problems of waste in research [75]. Overall, the included studies were not of high quality (from a risk of bias perspective). In addition, the reported data was simply not included by the authors in many cases. This was seen in the reporting of variance around DMFT/dmft values, and in authors' frequent failure to report underlying data on decayed, missing and filled teeth values which precluded calculation of CI and RI indices. Finally, even when this was reported, there were no variance values in any of the studies. Improved reporting and including detailed datasets would significantly reduce this problem and improve the quality of subsequent secondary data analysis in systematic reviews.

The impact that a disability has on different aspects of life will vary widely from person to person, depending on factors such as the level of support from family, friends and carers. It is possible that there is no difference seen in children with learning disabilities as a group because these factors play more of a role in their oral health than their disability. In many ways this would be similar globally to CNLD as their socio-economic status seems to be one of the main factors in determining whether they experience dental caries and receive care.
The overall lower permanent tooth CI in CLD may be due to several barriers to treating those children; practitioners' reluctance, lack of confidence, lack of training, lack of access to specialist provision, reluctance to refer children with significant additional care and support needs to GA, genuine difficulty, and a lack of behavioural and communication support. Although the data show a tendency for CLD to have their permanent teeth managed with more extractions than restoration treatments compared with CNLD, there is no further information from these studies on why this might be and again, it may be due to barriers to provision of care.

\section{Conclusions}

1. Overall, there was no evidence that children with learning disabilities have different levels of dental caries in their permanent or primary dentition, to children without learning disabilities.

2. When the types of disabilities were separated out, there was evidence of lower levels of dental caries in children with Down syndrome in the permanent dentition, however, this could be linked to delayed tooth eruption. There was no evidence of a difference for children with autism or mixed learning disabilities.

3. There is some evidence of a difference in the amount and type of dental care provided for CLD based on quantitative (using the care and restorative indices) and narrative data, but this is sparse and this area should be strengthened by better reporting of datasets.

\section{Additional file}

Additional file 1: Appendix 1: Newcastle-Ottawa Scale Risk of Bias Matrix; Appendix 2: data extraction tables from included studies. (DOCX $130 \mathrm{~kb}$ )

\section{Acknowledgements}

The review authors would like to acknowledge and extend our gratitude to Miss V Pickering, University of Dundee, for her administrative assistance with the sourcing of journal articles and compilation of reference lists.

\section{Declaration}

The authors declare no potential conflicts of interest with respect to the authorship and/or publication of this article.

\section{Authors' contributions}

$\mathrm{MR}$ and $\mathrm{NI}$ conceived and designed this review. MR, NI and MPA extracted the data. FS carried out statistical data analysis and investigation for publication bias. SM designed and ran the database searches. MR, NI, MPA, $F S, J R, J H$ interpreted the data and drafted the manuscript. All authors critically viewed the data, revised the manuscript, gave final approval and agreed to be accountable for all aspects of the work.

\section{Funding}

The authors' institutions supported the execution of this study and no external sources of funding has been received. 


\section{Availability of data and materials}

The extracted data from individual papers within this review are available in Additional file 1: Appendix 2.

\section{Ethics approval and consent to participate}

Not applicable.

\section{Consent for publication}

Not applicable.

\section{Competing interests}

$M R, J H, J R, F S, M P A, S M, N l$ : the authors declares that they no financial or non-financial competing interests related to this work.

\section{Author details}

'School of Dentistry, University of Dundee, Park Place, Dundee DD1 4HR, UK. ${ }^{2}$ Department of Operative and Preventive Dentistry, Charité Universitätsmedizin Berlin, Berlin, Germany. ${ }^{3}$ School of Dentistry, University of São Paulo, São Paulo, Brazil. ${ }^{4}$ Community \& Special Care Dentistry and Paediatric Dentistry, Charles Clifford Dental Services, Sheffield Teaching Hospitals NHS Foundation Trust, Sheffield, UK. ${ }^{5}$ Dundee University Library, University of Dundee, Dundee, UK.

\section{Received: 1 August 2018 Accepted: 22 May 2019}

\section{Published online: 15 July 2019}

\section{References}

1. Emerson E. Deprivation, ethnicity and the prevalence of intellectual and developmental disabilities. J Epidemiol Community Health. 2012;66(3): 218-24.

2. Waldron C, Phadraig M, Nunn J, Comiskey C, Donnelly-Swift E, Guerin S, et al. Oral hygiene programmes for people with intellectual disabilities. Cochrane Database Syst Rev. 2019;(5):CD012628. https://doi.org/10.1002/ 14651858.CD012628.pub2.

3. Lancioni GE, O'Reilly MF. Teaching food preparation skills to people with intellectual disabilities: a literature overview. J Appl Res Intellect Disabil. 2002;15(3):236-53.

4. Mencap. Mencap; the voice of learning disability. [cited 20/11/2017]; Available from: https://www.mencap.org.uk

5. Allerton LA, Welch V, Emerson E. Health inequalities experienced by children and young people with intellectual disabilities: a review of literature from the United Kingdom. J Intellect Disabil. 2011;15(4):269-78.

6. Jansen DE, Krol B, Groothoff JW, Post D. People with intellectual disability and their health problems: a review of comparative studies. J Intellect Disabil Res. 2004;48(Pt 2):93-102.

7. Marmot M. The Marmot review final report: fair society, healthy lives: strategic review of health inequalities in England post-2010. London: University College; 2010

8. Anders PL, Davis EL. Oral health of patients with intellectual disabilities: a systematic review. Spec Care Dentist. 2010;30(3):110-7.

9. da Silva SN, Gimenez T, Souza RC, Mello-Moura ACV, Raggio DP, Morimoto $S$, et al. Oral health status of children and young adults with autism spectrum disorders: systematic review and meta-analysis. Int J Paediatr Dent. 2017;27(5):388-98.

10. Moreira MJ, Schwertner C, Jardim JJ, Hashizume LN. Dental caries in individuals with Down syndrome: a systematic review. Int J Paediatr Dent. 2016;26(1):3-12

11. Zhou N, Wong HM, Wen YF, McGrath C. Oral health status of children and adolescents with intellectual disabilities: a systematic review and metaanalysis. Dev Med Child Neurol. 2017;59(10):1019-26.

12. Sgan-Cohen HD, Evans RW, Whelton H, Villena RS, MacDougall M, Williams DM, et al. IADR global Oral health inequalities research agenda (IADRGOHIRA(R)): a call to action. J Dent Res. 2013;92(3):209-11.

13. Shahtahmasebi S, Emerson E, Berridge D, Lancaster G. Child disability and the dynamics of family poverty, hardship and financial strain: evidence from the UK. J Soc Policy. 2011;40(4):653-73.

14. Moher D, Shamseer L, Clarke M, Ghersi D, Liberati A, Petticrew M, et al. Preferred reporting items for systematic review and meta-analysis protocols (PRISMA-P) 2015 statement. Syst Rev. 2015;4(1):1

15. Al Habashneh R, Al-Jundi S, Khader $Y$, Nofel N. Oral health status and reasons for not attending dental care among 12- to 16-year-old children with Down syndrome in special needs centres in Jordan. Int J Dent Hyg. 2012;10(4):259-64

16. Al-Maweri SA, Halboub ES, Al-Soneidar WA, Al-Sufyani GA. Oral lesions and dental status of autistic children in Yemen: A case-control study. J Int Soc Prev Community Dent. 2014;4(Suppl 3):S199-203.

17. AlSarheed M. A comparative study of oral health amongst trisomy 21 children living in Riyadh, Saudi Arabia: part 1 caries, malocclusion, trauma. Saudi Dent J. 2015;27(4):220-3.

18. Areias C, Sampaio-Maia B, Macho V, Leal I, Melo P, de Andrade C. Does the chemistry in the saliva of Down syndrome children explain their low caries prevalence? Eur J Paediatr Dent. 2013;14(1):23-6.

19. Bhandary S, Hari N. Salivary biomarker levels and oral health status of children with autistic spectrum disorders: a comparative study. Eur Arch Paediatr Dent. 2017;18(2):91-6.

20. Cornejo LSZ, A G, Dorronsoro de Cattoni ST, Calamari SE, Azcurra Al, Battellino LJ. Bucodental health condition in patients with Down syndrome of Cordoba City, Argentina. Acta Odontol Latinoam. 1996:9(2):65-79.

21. Davidovich E, Aframian DJ, Shapira J, Peretz B. A comparison of the sialochemistry, oral $\mathrm{pH}$, and oral health status of Down syndrome children to healthy children. Int J Paediatr Dent. 2010;20(4):235-41.

22. El Khatib AA, El Tekeya MM, El Tantawi MA, Omar T. Oral health status and behaviours of children with autism Spectrum disorder: a case-control study. Int J Paediatr Dent. 2014;24(4):314-23.

23. Fakroon S, Arheiam A, Omar S. Dental caries experience and periodontal treatment needs of children with autistic spectrum disorder. European archives of Paediatric dentistry: official journal of the European academy of Paediatric. Dentistry. 2015;16(2):205-9.

24. Forsberg H, Quick-Nilsson I, Gustavson KH, Jagell S. Dental health and dental care in severely mentally retarded children. Swed Dent J. 1985;9(1): $15-28$.

25. Hashizume LN, Schwertner C, Moreira MJS, Coitinho AS, Faccini LS. Salivary secretory IgA concentration and dental caries in children with Down syndrome. Special care in dentistry: official publication of the American association of hospital dentists, the academy of dentistry for the handicapped, and the American society for geriatric. Dentistry. 2017;37(3):115-9.

26. Jaber MA. Dental caries experience, oral health status and treatment needs of dental patients with autism. J Appl Oral Sci. 2011;19(3):212-7.

27. Mathias MF, Simionato MR, Guare RO. Some factors associated with dental caries in the primary dentition of children with Down syndrome. Eur J Paediatr Dent. 2011;12(1):37-42.

28. Moreira RN, Alcantara CE, Mota-Veloso I, Marinho SA, Ramos-Jorge ML, Oliveira-Ferreira F. Does intellectual disability affect the development of dental caries in patients with cerebral palsy? Res Dev Disabil. 2012;33(5): 1503-7.

29. Subramaniam P, Girish Babu K, Mohan Das L. Assessment of salivary total antioxidant levels and oral health status in children with Down syndrome. Special care in dentistry: official publication of the American association of hospital dentists, the academy of dentistry for the handicapped, and the American society for geriatric. Dentistry. 2014;34(4):193-200.

30. Yashoda R, Puranik MP. Oral health status and parental perception of child oral health related quality-of-life of children with autism in Bangalore, India. J Indian Soc Pedod Prev Dent. 2014;32(2):135-9.

31. Higgins JP, Thompson SG. Quantifying heterogeneity in a meta-analysis. Stat Med. 2002;21(11):1539-58

32. Egger M, Davey Smith G, Schneider M, Minder C. Bias in meta-analysis detected by a simple, graphical test. Bmj. 1997;315(7109):629-34.

33. Margulis AV, Pladevall M, Riera-Guardia N, Varas-Lorenzo C, Hazell L, Berkman ND, et al. Quality assessment of observational studies in a drugsafety systematic review, comparison of two tools: the Newcastle-Ottawa scale and the RTI item bank. Clin Epidemiol. 2014;6:359-68.

34. Areias CM, Sampaio-Maia B, Guimaraes H, Melo P, Andrade D. Caries in Portuguese children with Down syndrome. Clinics (Sao Paulo). 2011;66(7): 1183-6.

35. Altun C, Guven G, Akgun OM, Akkurt MD, Basak F, Akbulut E. Oral health status of disabled individuals attending special schools. Eur J Dent. 2010;4(4):361-6.

36. Areias C, Sampaio-Maia B, Pereira Mde L, Azevedo A, Melo P, Andrade C, et al. Reduced salivary flow and colonization by mutans streptococci in children with Down syndrome. Clinics (Sao Paulo). 2012;67(9):1007-11.

37. Mohinderpal Chadha G, Kakodkar P, Chaugule V, Nimbalkar V. Dental survey of institutionalized children with autistic disorder. Int J Clin Pediatr Dent. 2012;5(1):29-32 
38. Bakarcic DP, Ivancic-Jokic N, Bilic I, Lajnert V, Bukovic D. Dental status as a quality control health care parameter for children with disabilities. Coll Antropol. 2009;33(1):139-42.

39. Fahlvik-Planefeldt CH. P. Dental care of autistic children within the nonspecialized public dental service. Swed Dent J. 2001;25(3):113-8.

40. Fuertes-González MC, Silvestre FJ. Oral health in a group of patients with Rett syndrome in the regions of Valencia and Murcia (Spain): A case-control study. Med Oral Patol Oral Cir Bucal. 2014;19(6):e598-604.

41. Fung K, Lawrence $H$, Allison P. A paired analysis of correlates of dental restorative care in siblings with and without Down syndrome. Spec Care Dentist. 2008;28(3):85-91.

42. Lowe OL. R. Assessment of the autistic patient's dental needs and ability to undergo dental examination. ASDC J Dent Child. 1985;52(1):29-35.

43. Macho V, Palha M, Macedo AP, Ribeiro O, Andrade C. Comparative study between dental caries prevalence of Down syndrome children and their siblings. Special care in dentistry: official publication of the American association of hospital dentists, the academy of dentistry for the handicapped, and the American society for geriatric. Dentistry. 2013;33(1):2-7.

44. Mattila MLR.; Paunio, P.; Hyssala, L.; Helenius, H.; Sillanpaa, M.; Ojanlatva, A. Impact of dental health care on dental health of children with long-term diseases: a nested case-control study. J Clin Dent. 2001;12(3):77-82.

45. Oredugba FA. Oral health condition and treatment needs of a group of Nigerian individuals with Down syndrome. Downs Syndr Res Pract. 2007; 12(1):72-6.

46. Pollard MA, Curzon ME. Dental health and salivary Streptococcus mutans levels in a group of children with heart defects. Int J Paediatr Dent. 1992; 2(2):81-5.

47. Purohit BM, Acharya S, Bhat M. Oral health status and treatment needs of children attending special schools in South India: a comparative study. Special care in dentistry: official publication of the American association of hospital dentists, the academy of dentistry for the handicapped, and the American society for geriatric. Dentistry. 2010;30(6):235-41.

48. Radha $G$, Swathi $V$, Jha A. Assessment of salivary and plaque $\mathrm{pH}$ and oral health status among children with and without intellectual disabilities. J Indian Soc Pedod Prev Dent. 2016;34(3):257-61.

49. Du RY, Yiu CK, King NM, Wong VC, McGrath CP. Oral health among preschool children with autism spectrum disorders: A case-control study. Autism. 2015;19(6):746-51.

50. Rai K, Hegde AM, Jose N. Salivary antioxidants and oral health in children with autism. Arch Oral Biol. 2012;57(8):1116-20.

51. Vishnu Rekha C, Arangannal P, Shahed H. Oral health status of children with autistic disorder in Chennai. European archives of Paediatric dentistry: official journal of the European academy of Paediatric. Dentistry. 2012;13(3):126-31.

52. Ruiz LA, Diniz MB, Loyola-Rodriguez JP, Habibe CH, Garrubbo CC, Santos MT. A controlled study comparing salivary osmolality, caries experience and caries risk in patients with cerebral palsy. Medicina Oral. Patologia Oral Y Cirugia Bucal. 2018;23(2):e211-e5.

53. Sarnat H, Samuel E, Ashkenazi-Alfasi N, Peretz B. Oral health characteristics of preschool children with autistic syndrome disorder. J Clin Pediatr Dent. 2016;40(1):21-5.

54. Shaw L, Maclaurin ET, Foster TD. Dental study of handicapped children attending special schools in Birmingham, UK. Community Dent Oral Epidemiol. 1986;14(1):24-7.

55. Suhaib F, Saeed A, Gul H, Kaleem M. Oral assessment of children with autism spectrum disorder in Rawalpindi, Pakistan. Autism. 2017;01: 1362361317730299 .

56. Subramaniam P, Gupta M. Oral health status of autistic children in India. J Clin Pediatr Dent. 2011;36(1):43-7.

57. Weckwerth SA, Weckwerth GM, Ferrairo BM, Chicrala GM, Ambrosio AM Toyoshima GH, et al. Parents' perception of dental caries in intellectually disabled children. Special care in dentistry: official publication of the American association of hospital dentists, the academy of dentistry for the handicapped, and the American society for geriatric. Dentistry. 2016;36(6):300-6.

58. Namal N, Vehit HE, Koksal S. Do autistic children have higher levels of caries? A cross-sectional study in Turkish children. J Indian Soc Pedod Prev Dent. 2007;25(2):97-102.

59. Jokic NIM, Bakarcic D, Katalinic A, Szirovicza L. Dental caries in disabled children. Coll Anthropol. 2007:31(1):321-4.

60. Palin T, Hausen H, Alvesalo L, Heinonen OP. Dental health of 9--10-year-old mentally retarded children in eastern Finland. Community Dent Oral Epidemiol. 1982;10(2):86-90.
61. Lee SR, Kwon HK, Song KB, Choi YH. Dental caries and salivary immunoglobulin A in Down syndrome children. J Paediatr Child Health. 2004;40(9-10):530-3.

62. Pope JE, Curzon ME. The dental status of cerebral palsied children. Pediatr Dent. 1991;13(3):156-62.

63. Stabholz AM, Sela M, Schurr D, Steinberg D, Shapira J. Caries experience, periodontal treatment needs, salivary $\mathrm{pH}$, and Streptococcus mutans counts in a preadolescent Down syndrome population. Spec Care Dentist. 1991; 11(5):203-8.

64. Bakry NS, Alaki SM. Risk factors associated with caries experience in children and adolescents with intellectual disabilities. J Clin Pediatr Dent. 2012;36(3):319-23.

65. Cogulu D, Sabah E, Kutukculer N, Ozkinay F. Evaluation of the relationship between caries indices and salivary secretory lgA, salivary $\mathrm{pH}$, buffering capacity and flow rate in children with Down's syndrome. Arch Oral Biol. 2006;51(1):23-8.

66. Bakry NS, Alaki SM. Risk factors associated with caries experience in children and adolescents with intellectual disabilities. J Clin Pediatr dent. 2012;36(3):319-23.

67. Cornejo LS, Zak GA, Dorronsoro de Cattoni ST, Calamari SE, Azcurra Al, Battellino LJ. Bucodental health condition in patients with Down syndrome of Cordoba City, Argentina. Acta Odontol Latinoam. 1996;9(2):65-79.

68. Fahlvik-Planefeldt C, Herrstrom P. Dental care of autistic children within the non-specialized. Public Dental Service Swed Dent J. 2001;25(3):113-8.

69. Stabholz A, Mann J, Sela M, Schurr D, Steinberg D, Shapira J. Caries experience, periodontal treatment needs, salivary $\mathrm{pH}$, and Streptococcus mutans counts in a preadolescent Down syndrome population. Spec Care Dentist. 1991;11(5):203-8

70. Fakroon S, Arheiam A, Omar S. Dental caries experience and periodontal treatment needs of children with autistic spectrum disorder. Eur Arch Paediatr Dent. 2015;16(2):205-9.

71. Reid SM, Meehan EM, Arnup SJ, Reddihough DS. Intellectual disability in cerebral palsy: a population-based retrospective study. Dev Med Child Neurol. 2018;60(7):687-94.

72. Fung $K$, Allison PJ. A comparison of caries rates in non-institutionalized individuals with and without Down syndrome. Special care in dentistry: official publication of the American association of hospital dentists, the academy of dentistry for the handicapped, and the American society for geriatric. Dentistry. 2005;25(6):302-10.

73. Gupta E, Innes N, Schuller AA, Vermaire JH, Marshman Z. A scoping review of the uses of the care index in children. Community Dent Health. 2017; 34(3):131-6.

74. Deeks JJ, Higgins JPT, Altman DG. Analysing data and undertaking metaanalyses. Cochrane handbook for systematic reviews of interventions: Cochrane book series; 2008. p. 243-96.

75. Glasziou P, Altman DG, Bossuyt P, Boutron I, Clarke M, Julious S, et al. Reducing waste from incomplete or unusable reports of biomedical research. Lancet. 2014;383(9913):267-76

\section{Publisher's Note}

Springer Nature remains neutral with regard to jurisdictional claims in published maps and institutional affiliations.

\section{Ready to submit your research? Choose BMC and benefit from:}

- fast, convenient online submission

- thorough peer review by experienced researchers in your field

- rapid publication on acceptance

- support for research data, including large and complex data types

- gold Open Access which fosters wider collaboration and increased citations

- maximum visibility for your research: over $100 \mathrm{M}$ website views per year

At $\mathrm{BMC}$, research is always in progress.

Learn more biomedcentral.com/submission 